\title{
Design and Simulation of a Decentralized Railway Traffic Control System
}

\author{
Tolgay Kara \\ EEE Dept, University of Gaziantep \\ Gaziantep, Turkey \\ kara@gantep.edu.tr
}

\author{
M. Cengiz Savaş \\ Turkish State Railways Corporation (TCDD) \\ Gaziantep, Turkey \\ cengizsavas@hotmail.com
}

\begin{abstract}
With the increasing use of railway transportation, various methods have been developed for the control and management of train traffic. Train traffic control systems that are currently in use are overwhelmingly centralized systems. In this study, the development of the general structure of railway traffic control techniques is examined, centralized and decentralized control systems are investigated, and an alternative train traffic control system, the Decentralized Train Traffic Management System (DTMS), is suggested. Simulation results on the possible application of the proposed method to a railway line in South-East Turkey are employed to evaluate the performance of the developed system.
\end{abstract}

Keywords-Train Traffic Control; Railway Traffic; Decentralized Control; Decentralized Train Traffic Management System

\section{INTRODUCTION}

Management and control of railway traffic has been an appealing field of research in recent years. Reliable and fast train traffic control systems are needed to cope with the increasing traffic density and high speed trains of today. In the last few decades, the common approach to train traffic control has been the use of Automatic Train Control (ATC) systems along with radio communication. In Europe, the commonly used ATC system is the European Train Control System (ETCS) and Global System for Mobile Communications for Railways (GSM-R) is the basis of the radio communication functions of Level 1 with radio infill, Level 2 and Level 3. Combination of ETCS and GSM-R constitutes the European Railway Traffic Management System (ERTMS) [1, 2]. The majority of Railway Traffic Management (RTM) systems currently in use today are centralized systems where train traffic is monitored and controlled by a supervisor. Train traffic control is managed by a single center in many countries, whereas in Turkey different regions are controlled by separate control centers, which are unable to follow or control the operations of other regions. In Turkey, train traffic operations are managed by the use of traffic signals. Train positions are sensed and notified to the control center via rail track circuits wired to the control centers where available. Ordinary railway signal systems mainly consist of logic relay circuits, which need specific electric wiring. ATC systems receive data from trackside components by local wireless units [3]. In conventional train traffic management, it is necessary to develop a time distance diagram in order to determine and solve the problems of a railway system. In high-density lines this diagram cannot be recovered quickly since information of the train traffic in stations is insufficient or not available. The centralized train traffic control (CTC) system that uses telephone lines in Turkey is called TMI, where the train management by dispatchers and staff in the station is congested and effective working time of the staff for the maintenance work is reduced by telephone, as shown in Figure 1. TMI system used in many regions of Turkey remains weak and unreliable in many aspects [4]. An alternative to TMI tested in sections of railway network is the Global System for Mobile Communication (GSM) based version, shown in Figure 2. The railway network in the region of interest of this study is covered thoroughly by the GSM network supplied by a local operator and TMI-GSM system is practiced for the NARLINUSAYBIN line.

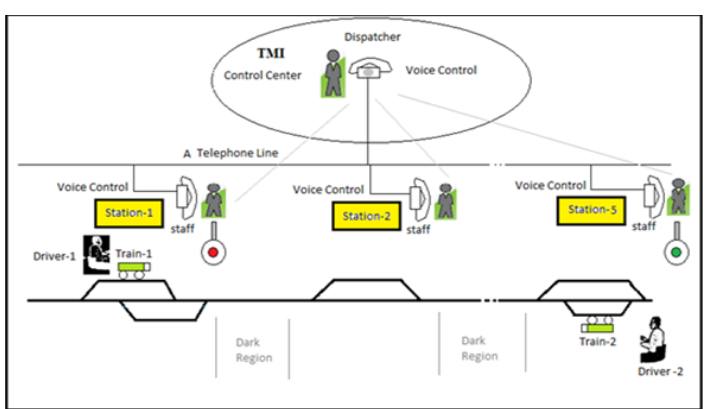

Fig. 1. Configuration of TMI System

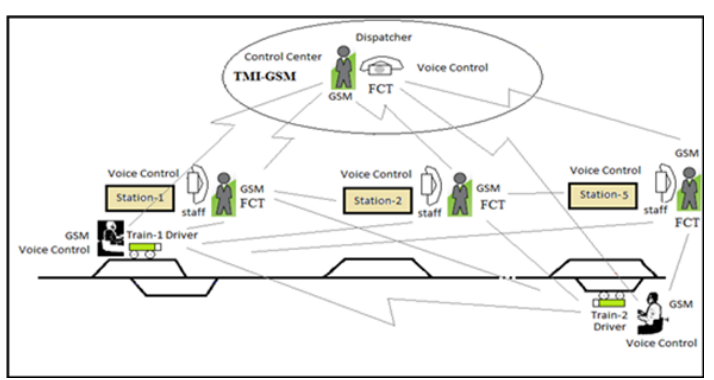

Fig. 2. Configuration of TMI-GSM System 
In the current study, a decentralized, flexible, low cost and reliable train traffic control system is investigated. Using simulations of a real railway line in Turkey, results illustrate the performance of the proposed system in usual and unusual scenarios.

\section{A GLANCE TO TRAIN TRAFFIC CONTROL}

In early years of railway transportation, railway companies used simple mechanical operation signals. The roadside employees transmitted the information during railway traffic and passed commands to the train drivers by means of flags or signs, manually. Then they would report the current situation of the train and line back to the control center. The control center handled all train traffic with this information [1]. Today, the methods of train traffic control and management vary from similar to these early practices to cutting edge high technology applications. Despite the fast progress and emerging methods in train traffic control, decentralized systems are still rare.

\section{A. A Review}

The ordinary signaling system mainly consists of logic circuits using relays, which need electric wiring. The Programmed Route Control (PRC) system is an automatic computer controlled system developed for the Sakaisuji Line in 1971 and Sanyo Shinkansen in 1972 instead of CTC, which is a system of manual control by dispatcher [5]. A different system was developed for driver errors in 1980's, when mechanical Automatic Train Stop (ATS) was used, and then electrical ATS was introduced along with line side equipment to prevent hazardous human errors. One advanced control method for train operation management developed in the 1980's was the predictive fuzzy system by the Hithachi Company in Japan. Yasunobu and Miyamoto suggested a fuzzy control system, which combined ATS with the Automatic Train Operation (ATO) system [6].

The first mention of a management system that is not centrally controlled was in [7]. A distributed approach to railway traffic control, which overcame the upper bounds imposed on the size of areas under control by the requirement for real-time processing when centralized methodologies are applied was described [7]. In a large scale critical real time control system, in [8] a real time control system constructed step by step over 8 years without halting train operations was reported. To enable testing during system operation, an autonomous decentralized online expansion technique was proposed, then the effectiveness of the technique was demonstrated in a real system [8]. The "Distributed Positive Train Control System" presented the idea of decentralized train traffic control in [9]. This system also aimed to control train movement in a distributed manner [9]. An autonomous decentralized traffic management system, different from the conventional CTC was described in [5]. The problems of Traffic Management Systems (TMS) were described and solutions were presented [5]. High degrees of safety and reliability in this system needed high assurance technologies in high density operational regions. This required the use of latest technologies of communication for reliability and safety [10]. Computer and internet technologies gradually had their impact on railway systems too. A novel railway control system that operated in a distributed fashion was proposed in [11]. In these years, the Thales Company developed Net-Trac 6617 CTC 1000. Every train moving along a line controlled by this system could be monitored and displayed on supervision pictures and time distance diagrams [12].

In Turkey, the most significant breakthrough in train traffic control in the last few decades took place in 2009 with the introduction of the national railway signaling project (UDSP) by the Turkish State Railways Corporation (TCDD) in cooperation with the Scientific and Technological Research Council of Turkey-Informatics and Information Security Research Center (TÜBİTAK-BİLGEM) and İstanbul Technical University. At a cost of 4.6 million pounds, the system was developed by Turkish engineers and for system testing purposes, MITHATPAŞA-ADAPAZARI Station was commissioned, the purpose of which is to facilitate the border crossing between EU countries [13]. Currently in Turkey, all railway traffic control systems have a centralized nature commanded by a dispatcher at the control center. Internet technologies and optics are used in the interlocking areas or in between control centers and local stations, one example of which is the Autonomous Decentralized Transport Operation Control System (ATOS), but railway traffic control system as a whole is CTC in nature [3]. The decentralized approach to control systems for railway traffic management is becoming popular with its lower costs and practicality [14].

\section{B. Conventional Train Traffic Control}

In RTM, electrical systems have replaced mechanical ones almost entirely today. Two common features of these systems are the central position of control or supervisory system and transmission of railway information by track circuits. Modern train control systems provide time-saving, traffic safety and efficient train management using ATC. ATC includes three subsystems; Automatic Train Protection (ATP), ATO, and ATS [1]. For the purpose of train control, the creation of a specific standard and the widespread use of it are required, so in European countries, ERTMS has been employed [2]. In recent years, ERTMS has been widely used in most European countries, and various signaling and control systems have been employed in other countries including Turkey to comply and communicate with ERTMS. New standards are being planned and established for the adaptation to ERTMS and its communication structure. In ERTMS, ATC systems are standardized in the context of ETCS, which has evolved in recent years in three levels: ETCS Level 1, Level 2, and Level 3. In Level 2 and Level 3, GSM-R communication system is integrated into ERTMS along with ETCS. The first two levels are depicted in Figure 3. ETCS Level 3, a radio-based system where track occupancy detection and marker board of roadside are not necessary, is still in testing phase [15].

\section{Future of Train Traffic Control}

One important problem of train traffic control is the need to ensure compliance and standard for the different train control systems. A solution to this problem is suggested to be ERTMS/ETCS [16-18]. In near future, railway lines will be 
used in a similar fashion to motorways. Different railway companies will be able to use the lines paying transit fees. They will have their own locomotives and track-mounted equipment and operate each train independently from other trains, which implies companies may need to have their own control system and track equipment. As a result of this necessity, on-board systems must be available and compatible with each other [14]. Current technology and future plans of public and private railway companies concentrate on a central train traffic control system that uses the best communication technologies, and permits integration of local central control systems into the network without any problem. However, this central approach will require extra effort to integrate systems. The new system proposed in this study will eliminate the necessity of this effort being a decentralized and modular system without any central control [19].
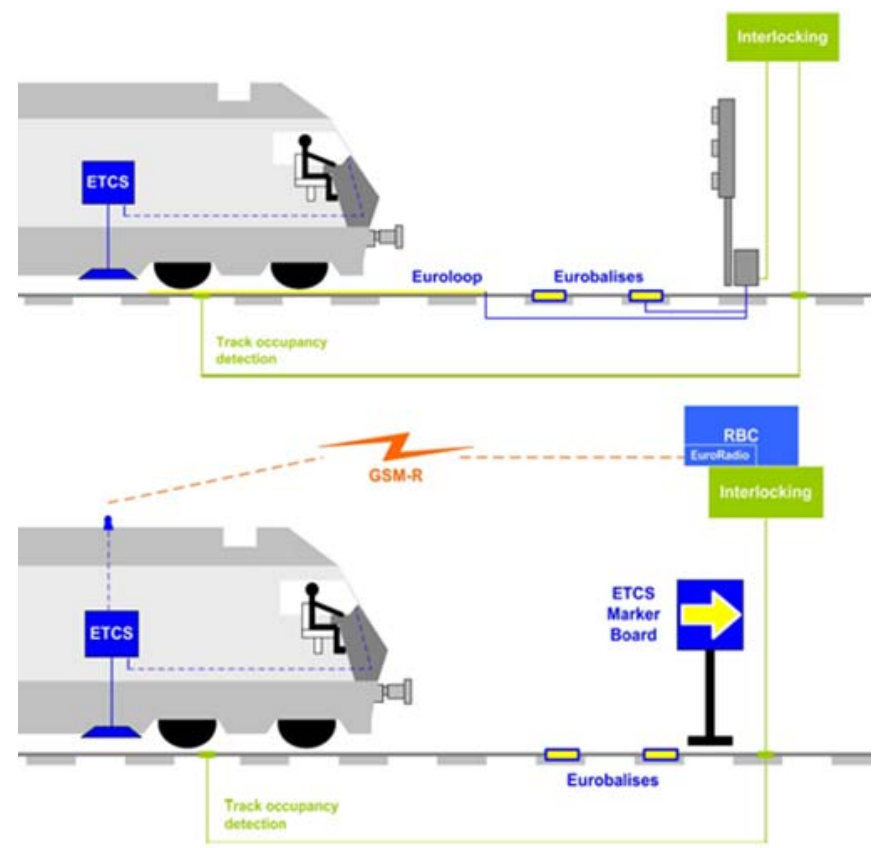

Fig. 3. ERTMS/ETCS Level 1 (a) and Level 2 (b).

\section{A NEW APPROACH: DTMS}

In this study, a decentralized train traffic control methodology that we call DTMS is presented. DTMS is developed as an alternative to the previously described conventional train traffic control systems and components needed for the implementation of DTMS are commercially available and $[20,21]$. In DTMS, every driver is able to monitor their own route via the Driver Machine Interface (DMI) system. Station personnel and dispatchers can monitor the whole region and drivers can communicate with stations, supervisors, and each other, eliminating the risk of blind spots in railway operations. In extraordinary circumstances, drivers and station personnel are notified immediately. The supervisors are able to control the system in cases of emergency and disable drivers with ATC/ATP/ATS if necessary. DTMS eliminates the need for field elements. DMI displays information about the situation along the road with the proper signal and gives according instructions. The most appropriate way to interact with the dispatcher and station personnel is maintained by the DTMS. If the operator of the system feels the necessity, switch positions can be submitted to the driver and changed by GSM-Data. The human factor for the control system is minimized in the proposed approach and investment costs are lowered by decreasing the number of personnel.

\section{A. Components and Communication System}

The main component of DTMS is a computer that has access to the internet, whose function is similar to the European Vital Computer (EVC) in ERTMS. The proposed system is designed to run in Microsoft operating systems for the time being, but it can be modified for compatibility with Linux based systems. The computer must be resistant to external disturbances such as vibration, heat, dust and shock in accordance with European standards. A $3 \mathrm{G}$ modem is required to connect to the internet via any operator. The GSM operator is assumed to cover the entire region and a GPS device is used to obtain time, speed, and position information of the train. Location data can also be received via the $3 \mathrm{G}$ modem for confirming the GPS. A schematic diagram of signal flow and control in the region as it is currently operated is given in Figure 4 and the diagram of the proposed DTMS is schematically presented in Figure 5. There is no need for roadside signals since all signals can be monitored from inside the locomotive. This signaling approach is a solution to the problem that roadside signals are difficult to follow at high speeds and the driver may not have sufficient time to react to a roadside signal in the conventional system. It also eliminates hazards that may arise due to roadside equipment failure or broken cables. In DTMS, communication is provided by a $3 \mathrm{G}$ modem. If $3 \mathrm{G}$ connection is interrupted, the GSM/GPRS support may be used. The driver manually inputs commands in accordance with supplied data and instructions by the DTMS, which are displayed on the DMI screen and read out loud simultaneously by the system.

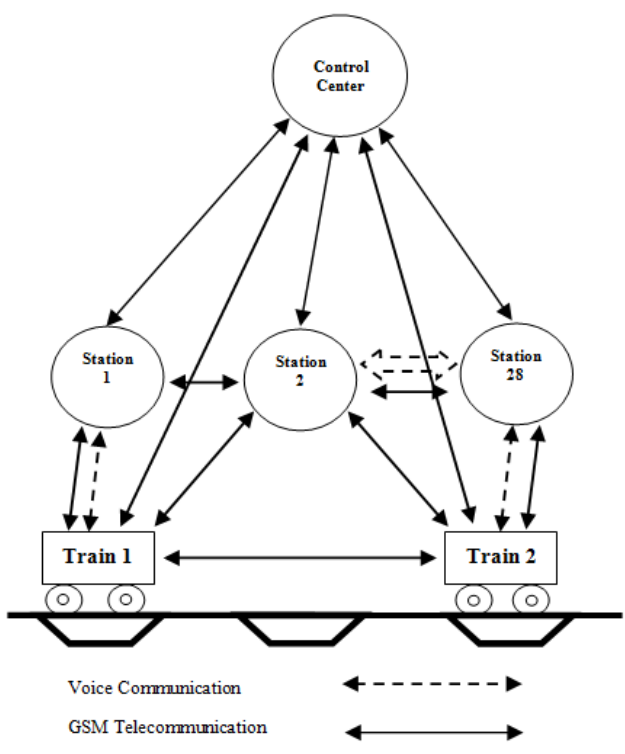

Fig. 4. Train Traffic Control Diagram of TMI-GSM 


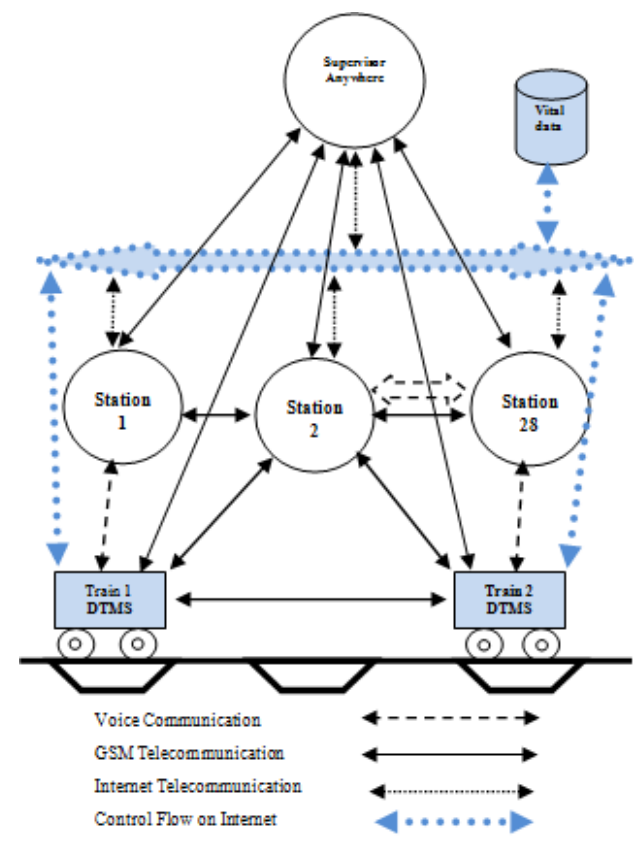

Fig. 5. Train Traffic Control Diagram of DTMS

\section{SOFTWARE FOR DTMS}

The DTMS software has been created using the Delphi programming language, and special attention has been paid that it complies with the rules and regulations of railway transport in Turkey. The functions of all users are unified in a single package. Upon arrival of the train to the station, DTMS program controls the train traffic automatically. A diagram of the algorithm in terms of data flow and decision processes is given in Figure 6. The driver must follow all directives on screen while DTMS processes the condition of the railway, the status of the train and other data such as speed, arrival time, departure time and destination station, and displays a green or red signal on DMI to handle the train traffic. When there is no emergency situation on the line, no train approaching from opposite direction, or a contradicting order from the supervisor, it is concluded that the route is available and the train motion can be started with a green signal. The software and log-in screen are common for each DTMS user. If the DTMS user is a train driver, they should input the driver number and password to access the DTMS interface. If the DTMS user is a supervisor, then what they need to do is input the supervisor number and password, and click on the button for the supervisor screen. The log-in screen of the DTMS software is shown in Figure 7. Examples of driver's and supervisor's view of DTMS are given in Figures 8 and 9, respectively.

\section{SimUlation OF DTMS}

\section{A. Assumptions and Application Area}

For the simulation of proposed DTMS, the program has been executed in accordance with a number of assumptions and a priori knowledge about the region of application. In train traffic management, straight roads are always easier to handle and curves are generally undesirable. The speed on a straight road is higher than the speed of diverse road because of switches of the railway. If the train is for passenger transport, preferred road of train is always the road where the passenger platform exists.

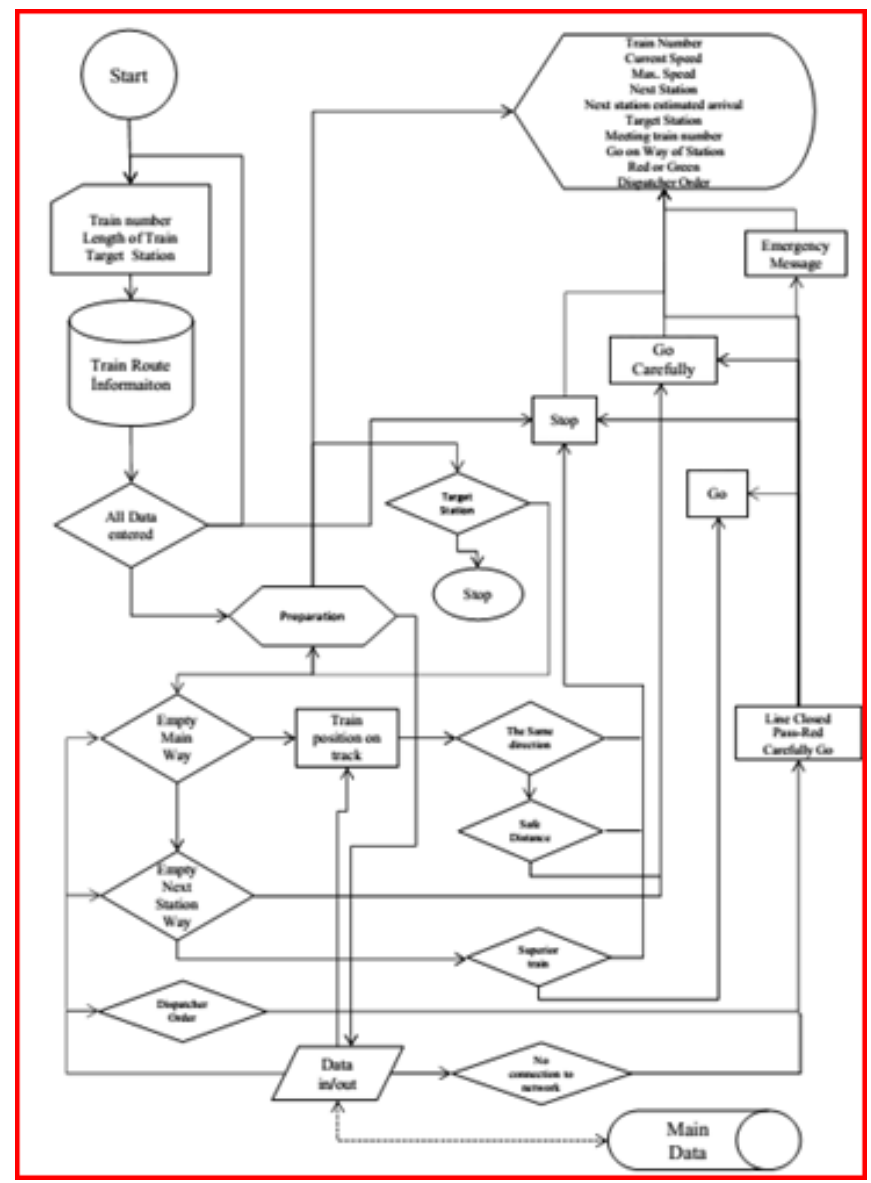

Fig. 6. Data flow and decision diagram of DTMS

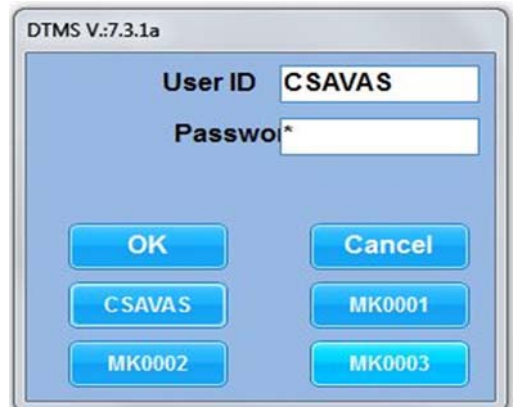

Fig. 7. Log-in Screen for DTMS

Switch positions are observed by means of switch lights, and the train must stop in front of the railway switch in TMI and TMI-GSM systems. Similarly, the train will stop in front of the switch, and then move according to the switch position in DTMS. All roads of the station and the main lines are identified in terms of length in kilometers. This length information 
combined with GPS and GPRS position data is processed in a database so that location can be accurately determined and reported to the system.

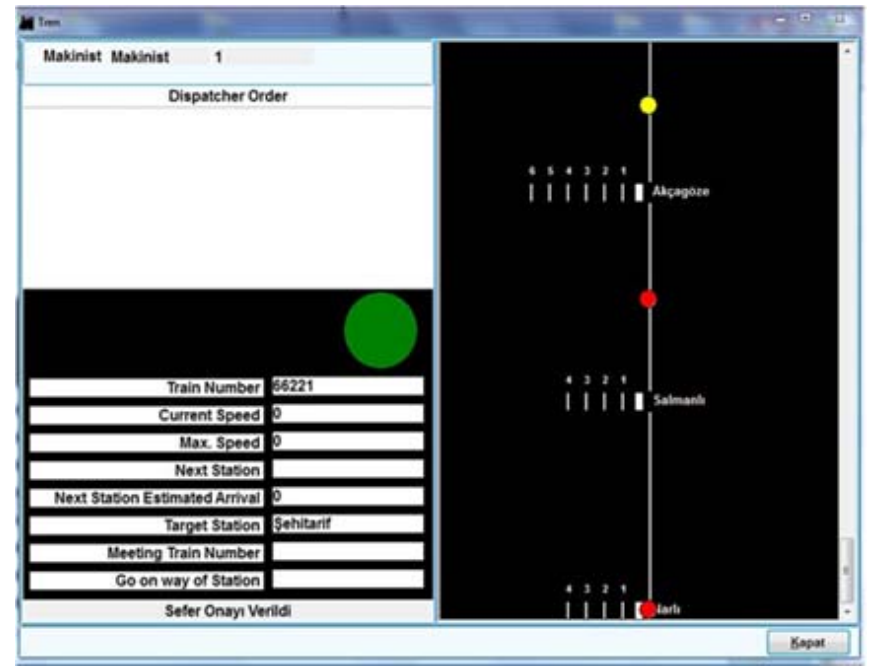

Fig. 8. Driver's view of DTMS

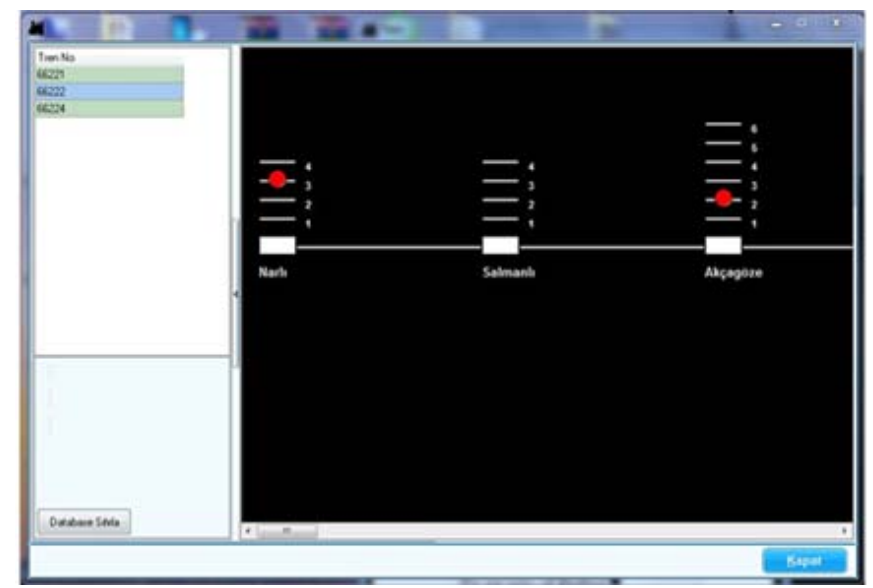

Fig. 9. Supervisor's view of DTMS

Commonly four roads in every station exist, two being in the east direction and two in the west direction. DTMS permits a maximum of three trains in every station in one direction and keeps one line as a spare for a possible train in opposite direction. All trains are numbered and it is assumed that, if the train number is known, then the direction of motion, type of train, region, and maximum speed are available.

In the region of application, which is the railway line between NARLI and GAZIANTEP stations as given in Figure 10, TMI-GSM is currently in use. TMI and TMI-GSM are basically two versions of the same system that differ in the used communication technology. In this area, there exists no signaling system or ATS, ATC, ATP system, its vehicles and field equipment. This region is the test area of TMI-GSM, which has been in use for five years. Dial up telephones are equipped with Fixed-to Cellular Terminal (FTC) and trains have mobile receivers. The entire region is covered by the GSM operator. During the application of GSM-supported communication and traffic control for more than five years, the system has proven itself as a flawless control system. TMI has been improved in quality of voice communication, which has made it easier for trains in motion and at stations to contact with the TMI-GSM center, as shown in Figure 2.

\section{B. Simulation Results}

Train traffic control in the region of application has been simulated in three scenarios for normal operation and an unusual case. The first two simulation tests are for the assessment of the proposed system as it controls the operation of the train traffic when no risk appears. The third scenario is simulated for testing a case where the trains move unexpectedly and some unusual traffic situations occur.

In Scenario I, Train A (TA) travels from NARLI to ŞEHITARIF, Train B (TB) travels from AKÇAGÖZE to NARLI, and Train C (TC) travels from ŞEHITARIF to NARLI. All trains depart simultaneously. The schematic diagram of the scenario is given in Figure 11. Time distance diagram for the current case of TMI and the proposed DTMS as simulated in accordance with the actual distances and train speeds is given in Figure 12. Two control methods result in the same travel times and dispatching schedules for this case. Evidently, DTMS follows accurately the planned train traffic, but does not improve the travel times.

Scenario II considers a more complicated traffic schedule. Here, TA and TB are supposed to travel from NARLI to ŞEHITARIF, while TC and Train D (TD) will move in the opposite direction from AKÇAGÖZE and ŞEHITARIF to NARLI, respectively. Diagram of the scheduled train traffic for Scenario II is presented in Figure 13. Simulation results reveal that both TMI and DTMS give the same time distance diagram that is presented in Figure 14. In this scenario, train traffic is controlled accurately as in TMI automatically by DTMS, and travel times are the same.

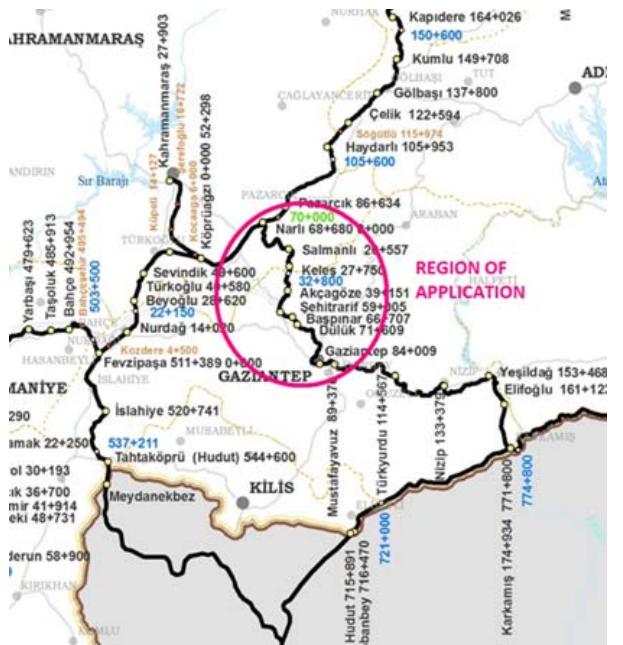

Fig. 10. Region of application for DTMS simulations: Narl1-Gaziantep railway line 
In Scenario III, as TA approaches ŞEHITTARIF, the driver is informed that all roads at the station are occupied by four trains at halt. In this scenario, TMI and DTMS yield different time distance diagrams. TMI, which manages this traffic situation using dispatchers' commands, keeps TA waiting at the nearest station to ŞEHITARIF until a road at the station is evacuated. However, DTMS takes into account the departure time of TB and estimated travel time of TA, and reaches the conclusion of a vacant road at destination. Consequently, DTMS permits a continuous trip from NARLI to ŞEHITARIF. Travel times of trains and total time saved by DTMS are given in Table I.

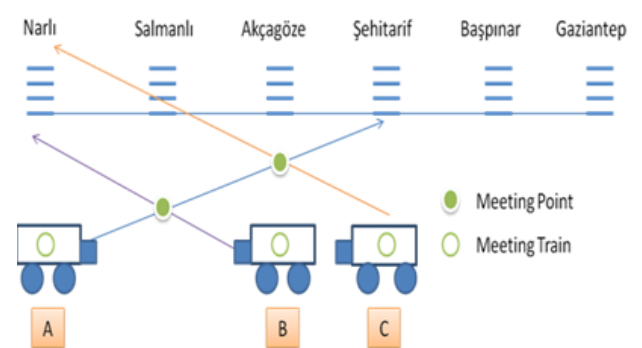

Fig. 11. Scheduled Train Traffic in Scenario I

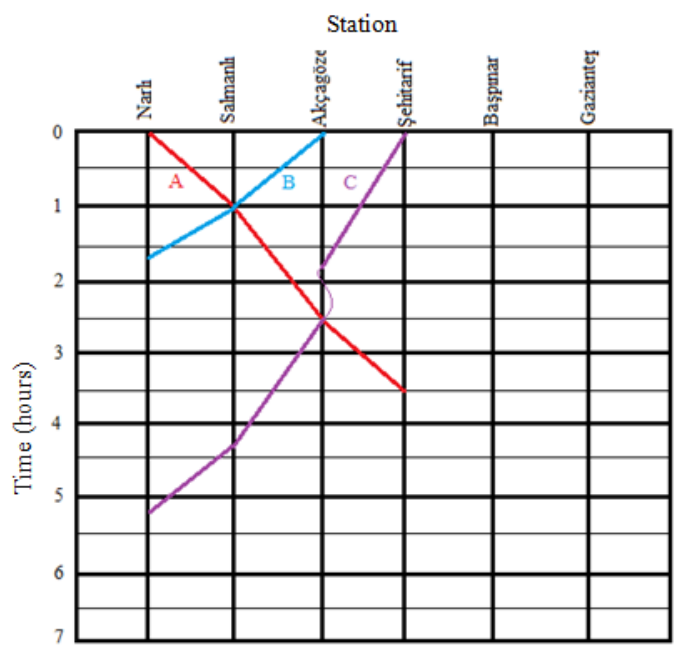

Fig. 12. Time distance diagram for Scenario I with TMI and DTMS

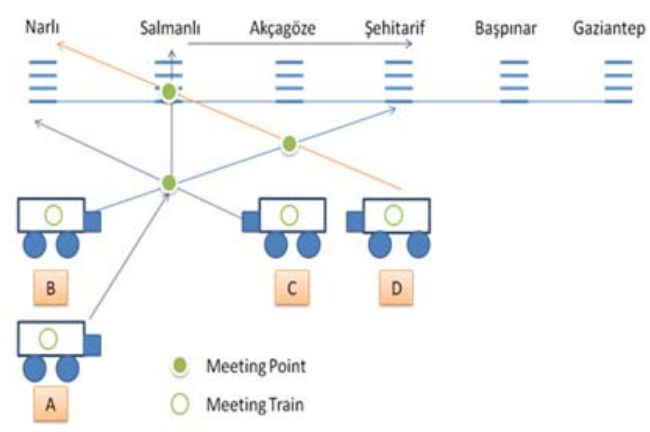

Fig. 13. Scheduled Train Traffic in Scenario II

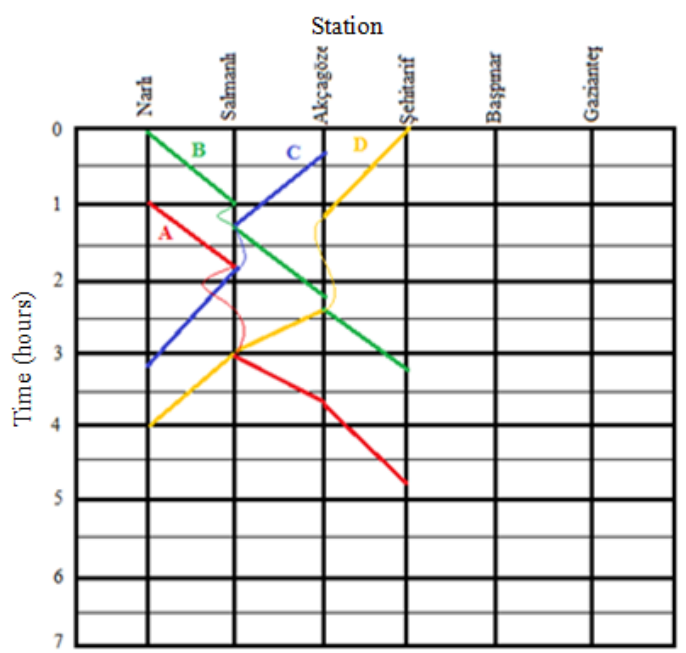

Fig. 14. Time distance diagram for Scenario II with TMI and DTMS

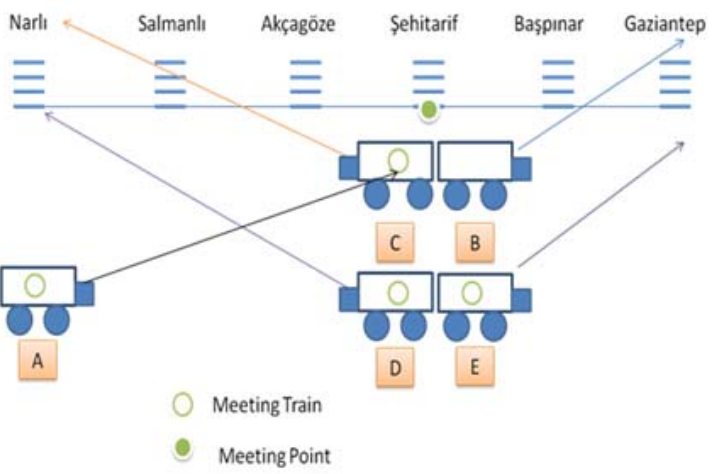

Fig. 15. Scheduled Train Traffic in Scenario III

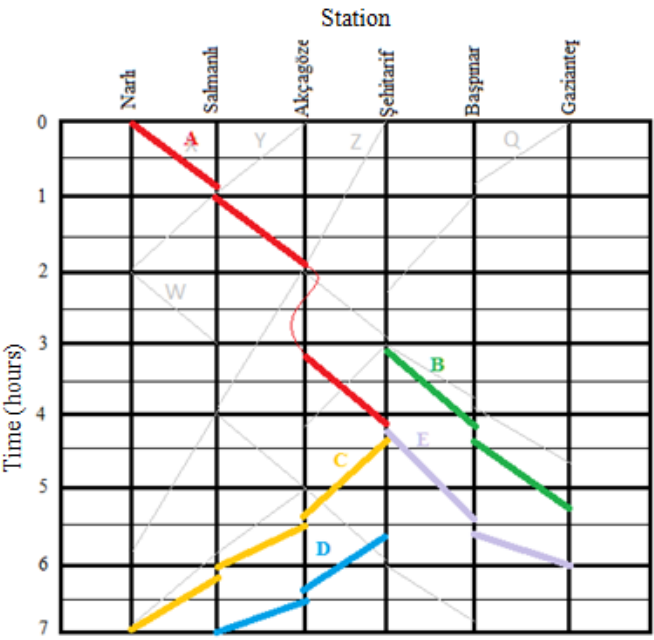

Fig. 16. Time distance diagram for Scenario III with TMI

In Table I, travel time is the total duration of time from departure to arrival, and dwell time is the total extra time spent at the stations when the train is at halt, which excludes loading 
and unloading times. Total time saved by DTMS in comparison with conventional TMI is at the last column. This saved time is generally a result of zero dwell time in DTMS, but train speeds between stations are also adjusted by DTMS for flawless operation, which results in saved time being less than or equal to the dwell time for each train.

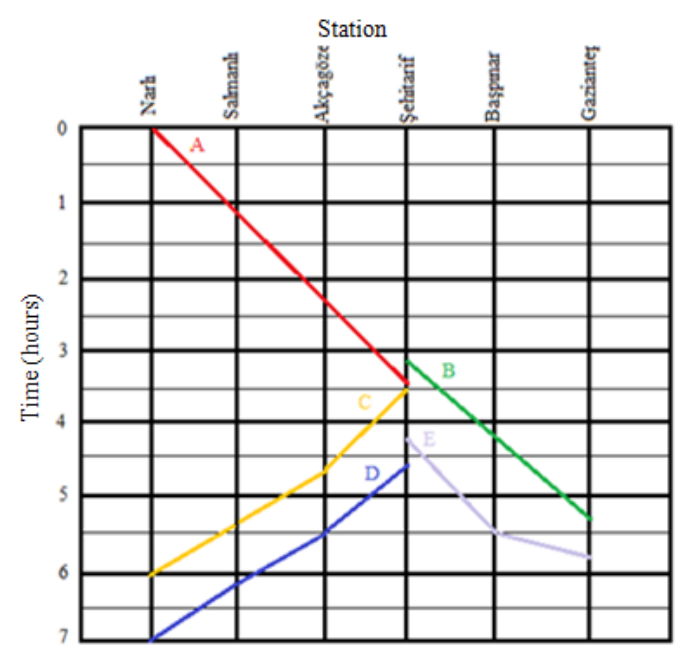

Fig. 17. Time distance diagram for Scenario III with DTMS

TABLE I. TRAVEL AND DWELL TIMES FOR TMI AND DTMS, AND TIME SAVED FOR SCENARIO III (ALL TIMES IN MINUTES)

\begin{tabular}{|c|c|c|c|c|c|}
\hline Train & $\begin{array}{c}\text { Travel } \\
\text { time for } \\
\text { TMI }\end{array}$ & $\begin{array}{c}\text { Travel } \\
\text { time for } \\
\text { DTMS }\end{array}$ & $\begin{array}{c}\text { Dwell } \\
\text { time for } \\
\text { TMI }\end{array}$ & $\begin{array}{c}\text { Dwell } \\
\text { time for } \\
\text { DTMS }\end{array}$ & $\begin{array}{c}\text { Time } \\
\text { saved by } \\
\text { DTMS }\end{array}$ \\
\hline TA & 250 & 205 & 80 & 0 & 45 \\
\hline TB & 130 & 125 & 15 & 0 & 5 \\
\hline TC & 160 & 150 & 10 & 0 & 10 \\
\hline TD & 145 & 140 & 5 & 0 & 5 \\
\hline TE & 105 & 90 & 10 & 0 & 15 \\
\hline
\end{tabular}

\section{CONCLUSION}

Train traffic control applications and related technologies are prominently appealing to researchers in recent years. Despite the progress in utilized technologies, the systems for train traffic control remain to be essentially and dominantly centralized (Centralized Traffic Control or CTC systems). Nevertheless, decentralized train traffic control may be promising as the future of Automatic Train Control (ATC). This study proposes a Decentralized Traffic Management System (DTMS), which has been designed, coded and simulated for a number of real cases. Simulations are executed for three scenarios, first two of which reveal the capacity of DTMS to attain the same traffic control goals of TMI automatically. This proves the power of DTMS to manage a train traffic situation without the need for supervisor and extra personnel for dispatching the trains. The third scenario investigates the assessment of DTMS in an unexpected traffic situation. The results prove that DTMS not only gives good ATC operation, but may also save significant amount of travel time, as all trains in this scenario completed the expedition without any problem in less time than TMI. DTMS is currently under inspection by Turkish Patent Institute (TPE) for domestic patenting. Future work is the implementation of DTMS to suitable lines of Turkish railway network.

\section{REFERENCES}

[1] R. Palacin, R. Mauck, Mapping Control Systems, Improving European Railways Retrack an EU-Project, EU 6th Framework Programme Project Report, 2011

[2] S. Dhahbi, A. Abbas-Turki, S. Hayat, A. El Moudni, "Study of the highspeed trains positioning system: European signaling system ERTMS/ETCS", 4th International Conference on Logistics, pp. 468-473, Hammamet, 2011

[3] Y. Çetin, Demiryollarında ATC ve ATO Sistemler, M.S. thesis, Dept. Elec. Electronics Eng., İnönü Univ., Malatya, Turkey, 2008

[4] Turkish Ministry of Education, Raylı Sistemler Teknolojisi: TMI sistemi, Educational Report, Ankara, 2011

[5] F. Kitahara, K. Kera, K. Bekki, "Autonomous Decentralized Traffic Management System”, Proc. of IEEE Assurance Conference, pp. 87-91, Chengdu, 2000

[6] S. Yasunobu, S. Miyamoto, "Automatic Train Operation system by Predictive Fuzzy Control", in Industrial Applications of Fuzzy Control, M. Sugeno (Ed.), pp. 1-18, 1985

[7] G. Vernazza, R. Zunino, “A Distributed Intelligence Methodology for Railway Traffic Control", IEEE Transactions on Vehicular Technology, vol. 39, No. , pp. 263-270, 1990

[8] F. Kitahara, T. Iwamoto, K. Kikuchi, K. Fujiwara, "Widely-distributed train-traffic computer control system and its step-by-step construction", 2nd International Symposium on Autonomous Decentralized Systems, (ISADS 95), pp. 93-102, Phoenix AZ, 1995

[9] J. B. Hungate, Distributed Positive Train Control System, US Patent, 1999

[10] M. Matsumoto, S. Kitamura, M. Sato, "High Assurance Technologies for Autonomous Decentralized Train Control System", 6th IEEE International Symposium on High Assurance Systems Engineering HASE'01, pp. 220-227, Boco Raton FL, 2001

[11] Y. Fukuta, G. Kogure, T. Kunufuji, H. Suguhara, R. Ishima, M. Matsumoto, "Novel Railway Signal Control System Based on the Internet Technology and Its Distributed Control Architecture", 8th International Symposium on Autonomous Decentralized Systems (ISADS'07), pp. 77-82, Sedona AZ, 2007

[12] Thales Group, Nettrac 6617 CTC 1000 Centralized Traffic Control System, Public Report, Thales Security Services and Solutions Division, 2007

[13] Republic of Turkey Ministry of Transport Maritime Affairs and Communication, Demiryolu, Public Report, 2013

[14] T. Kara, M. C. Savaş, "A Distributed Control System For Railway Traffic Management", International Federation of Automatic Control (IFAC), Turkish National Meeting on Automatic Control, TOK'12, pp. 349-354, Niğde University, 2012

[15] L. Aliadiere, R. Heinisch, "Global perspectives for ERTMS - ETCS and GSM-R”, ETF - Editions Techniques Ferroviaires, Railway Technical Publications, 2007

[16] C. R. Page, ERTMS for Australia, Westinghouse Signals Australia, Institution of Railway Signal Engineers Australian Section Inc, 2001

[17] Alstom Transport, An Advanced Communication Based Train Control System for Toronto, Public Report, 2010

[18] Transport Canada, Railway Signal and Traffic Control Systems Standards, Public Report, 2013

[19] A. S. Tanenbaum, M. van Steen, Distributed Systems Principles and Paradigms, Prentice Hall, US edition, 2002

[20] L. Bakule, "Decentralized Control: An Overview", Annual Reviews in Control, Vol. 32, pp. 87-98, 2008

[21] B. G. Liptak, H. Eren, Process Software and Digital Network, Instrument Engineers' Handbook, Fourth Edition, CRC press, USA, 2012 